and excretion are both rapid after dosage by ingestion; the blood level rises after about 100 minutes. Examination of blood and urine will indicate the extent of the absorption of molybdenum.

Parallel experiments on the relative toxicity of chromates, tungstates and molybdates of sodium by intraperitoneal injection show that the molybdate is the least, and the tungstates the most, toxic. Histological studies throughout these experiments show minimal changes. The liver shows fatty infiltration and small focal necroses. The findings suggest that the compounds of molybdenum in general are of low toxicity. In industry the worker should be protected from inhaling large quantities of the more soluble compounds.

$$
\text { J. N. Agate. . }
$$

\section{A MEDICAL STUDY OF THE EFFECT OF TNT ON WORKERS IN A BOMB AND SHELL LOADING PLANT}

\section{R. F. Seivers, A. H. Lawton, F. Skoog, P. A. Neal and W. F. von Oettingen and \\ REPORT OF FATAL CASE OF APLASTIC ANAEMIA}

R. L. Stump, A. R. Monaco and R. F. Sievers

Publ. Hlth. Bull., Wash., No. 291, 1945. (Pp. 98; refs. 70).

This is a painstaking study of 250 men and 103 women in contact with TNT, and of 55 men and 50 women controls, but little new is added to existing knowledge. For those who are unfamiliar with the methods employed in filling bombs and shells, the description and photographs of the process form the most valuable part of the report. No cases of severe TNT poisoning were seen, but 21 workers were considered to be suffering from early or mild TNT intoxication. No single test is diagnostic of TNT poisoning in its early stages. Workers exposed to TNT, but not showing signs of intoxication, showed a decrease in the haemoglobin, haematocrit reading, and red blood count, slightly increased in the icterus index, and urinary excretion of coproporphyrin. Snyder and von Oettingen's (U.S. Publ. Hlth. Bull., No. 285, 1943; and J. Amer. med. Ass., 1943, 123, 202) test for 2.6 di-nitro-4-aminotoluene (a metabolic product of TNT) in the urine, besides being quantitative, proved more sensitive than Webster's test as an index of absorption. The diet of all workers was good, but symptoms were more common in non-milk drinkers; the consumption of poly-vitamin capsules offered no protection. Men were more frequently affected than women, and the increased incidence of complaints in men was thought to be independent of the fact that the average duration of contact for men ( 8 months) was longer than that for women ( 3 months) or that men were employed on more dusty jobs. Loss of weight, if accompanied by other signs of TNT intoxication, was considered to be due to TNT. Compared with the control group, exposed workers complained more frequently of fatigue, malaise or drowsiness, anorexia and vomiting, abdominal pain, headache, dizziness, and polyuria. Cyanosis was observed among $68 \%$ of the exposed men and $36 \%$ of the exposed women, and pallor in $45 \%$ of the men and $41 \%$ of the women, but the pallor is unrelated to blood changes. Forty per cent. of the exposed groups complained of dermatitis at some time (usually in the first month). There were no significant cardiac changes.
A fatal case of aplastic anaemia following TNT hepatitis in a 43-year-old white male, after slight exposure to TNT, is reported. After he had complained of nausea, anorexia, constipation, sore throat, lumbar pains, burning of the eyes, and burning on micturition, it was discovered that he was jaundiced and that his liver was enlarged. The icterus index was 100 and Webster's test negative. The red cell count dropped from 4,010,000 to 2,730,000 per c.cm. of blood, and $\mathrm{Hb}$ from 15.0 to $7.5 \mathrm{gm}$. in 75 days. The white cell count fell to 2,400 per c.cm., and platelets disappeared. Folic acid was given too late to be effective. Histological section of the liver showed almost complete disappearance of the liver cells, but the bone marrow appeared of normal cellularity, with a few monoblasts and occasional erythroblasts. Granulocytes were rare and primitive.

\section{T. A. Lloyd Davies.}

\section{AN EXPERIMENTAL STUDY OF RATIONING}

By R. A. McCance and E. M. Widdowson (1946)

(Spec. Rep. Ser. Med. Res. Coun. Lond. No. 284. pp. 61. 1s.)

This is an account of an experiment carried out by eight people in which they rationed themselves to a diet which they considered might become necessary for the whole population if unrestricted submarine warfare was successful. Government departments are apt to attempt to suppress scientific information, and this activity can, in wartime, always masquerade under security. Now that this excuse can no longer be upheld, the Medical Research Council has adhered to its principles that scientific work must be published. Readers may judge for themselves how valid was the security excuse for suppressing this simple experiment which might have been repeated by anybody at any time, and give thought to the unhappy results which may occur when ministers and their bureaux have complete control of everything. The diet envisaged included 4 ozs. fat, 5 ozs. sugar including jam, 35 ozs. milk, 4 ozs. cheese, 16 ozs. meat, 6 ozs. bacon. The bread was made from flour of 92 per cent. extraction, while the consumption of potatoes and vegetables was unrestricted. During strenuous exercise, which included cycling 90 miles a day, or walking 38 miles a day in the Lake District, they sometimes ate as much as $3 \mathrm{lb}$. of potatoes, the calorie value of the diet being between 3,000 and 4,000 a day. Throughout the experiment all food was weighed and analysed in detail, and during three separate weeks faeces and urine were collected and analysed also in the greatest detail.

The experimenters kept to the diet for three months and at the end were very fit and could carry out satisfactorily, and without undue fatigue, most severe exercise tests, requiring a very high expenditure of energy. The results certainly show that young adults could have maintained a high standard of health under dietetic conditions much more austere than those actually experienced in the war. The authors could see no justification for the enormous amounts of meat in the rations of the soldier, and considered that troops, in this country, at any rate, would have been just as well served with bread made from lightly milled flour, more potatoes if necessary, and less meat. From these experiments it is not possible to say how children and old people would have fared under these dietary conditions, but it is probable that those who could eat the food allotted would have maintained good health.

K. M. A. Perry. 